\title{
DEVELOPMENT OF NETWORK-TYPE ARCHAEOLOGICAL INVESTIGATION SYSTEM
}

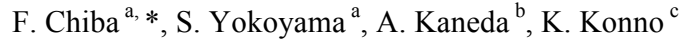 \\ ${ }^{\text {a }}$ LANG CO.,LTD, Morioka, Japan - (f-chiba, s-yokoyama)@lang-co.jp \\ ${ }^{\mathrm{b}}$ Nara National Research Institute for Cultural Properties, Nara, Japan - akaneda@nabunken.go.jp \\ ${ }^{\mathrm{c}}$ Iwate University, Morioka, Japan - konno@eecs.iwate-u.ac.jp
}

KEY WORDS: Archaeological Investigation System, Network, Underground Surveys, 3D Laser Scanner, Image Processing

\begin{abstract}
:
The Great East Japan Earthquake on March 11, 2011 is said to be a once-in-1000-year catastrophic quake. The Tsunami triggered by the earthquake destroyed broad coastal areas in northeast Japan. As recovery from the earthquake proceeds, the demand for new road construction, housing hill development, and residential construction is rapidly increasing. Culture plays a critical role in the district's recovery. For that reason, before development, cultural properties in the corresponding districts must be urgently investigated. This is a must, although balancing cultural recovery with rapid economic recovery is no easy task. With this in mind, we have developed a new system focusing on speedy archaeological investigation and adequate documentation. The authors reexamined the existing investigation process to categorize tasks into two types: those that must be done only at archaeological sites (site A) and ones available at other places (site B). We then formulated a scheme where the tasks on both sites are performed simultaneously in parallel over the network. Experiments are ongoing. This presentation reports the process and issues of our research and development.
\end{abstract}

\section{INTRODUCTION}

In Japan, if a ground assigned as an archaeological site is to be changed, the site must be investigated before the change and an investigation report must be issued. The local government with jurisdiction over archaeological sites has been handling the investigation and report issue. At present, to reconstruct the towns destroyed by the Great East Japan Earthquake in 2011, new projects are increasing rapidly for transporting residences to hills or constructing roads. In this situation, however, archaeological investigation is needed before such reconstruction and there are not enough experts for the investigation. If archaeological sites are investigated as in the past, the long investigation time will interfere with smooth recovery. So taking quick action on this issue is desirable.

Since 2012, the authors have been working to construct a system that shortens the investigation time and allows reports to be created quickly. This paper describes progress to date.

\section{METHODS}

Figure 1(a) shows how the archaeological investigation has been done. General archaeological sites are formed by soil layers accumulated over many years. Field investigation at archaeological sites comprises two tasks: excavation that removes soil layers from the top and drawing that forms line images of excavated remains. In the course of the process, the excavated relics are carried indoors, washed out, assigned IDs, and other elementary tasks are performed to create order. The relics are then drawn through archaeological observation. The record drawings obtained in field investigation and that obtained through indoor tasks are edited to issue an excavation report.

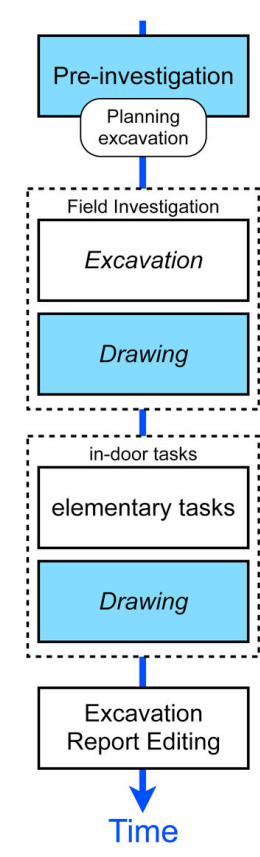

(a) Traditional

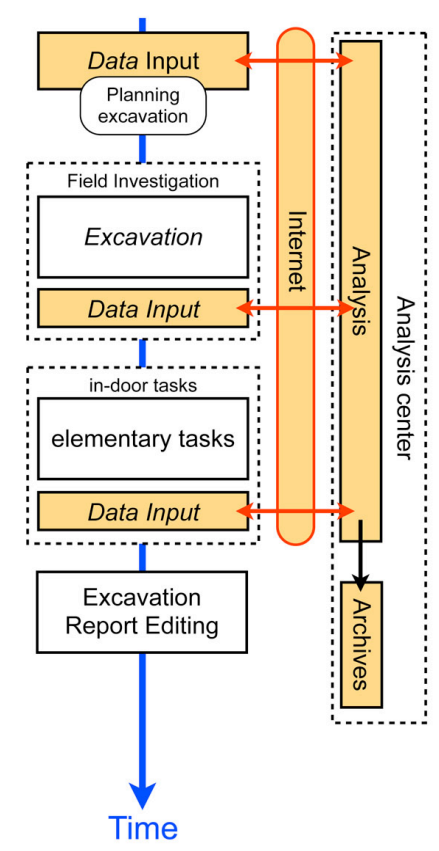

(b) New

Figure 1. Workflow of excavation investigation

The authors first addressed the current status of this workflow, which is performed by a fixed group with one or more experts at the corresponding archaeological sites or around them. The authors then assumed that the investigation would be completed more quickly if the tasks in this workflow were accomplished in parallel simultaneously with some regional support systems. Figure 1(b) shows the newly organized workflow. 
When an affected area (or site A) is excavated, an analysis center (or site B) is, at the same time, placed at a separate area to provide logistical support, and the two sites are connected through the Internet. At site $\mathrm{A}$, excavation and various data input are intensively performed. At site B, the data and images sent continually from site $\mathrm{A}$ are processed and the information is shared immediately with site A. By using personal, intellectual and physical networks like this, the tasks at site A, originally including various restrictions, are simplified and effective archaeological investigation are achieved.

The following three points need to be improved over the traditional excavation investigation process:

(1) Determining distribution of remains before investigation: In the traditional investigation process, distribution of archaeological remains were determined by excavating a test pit at an arbitrary interval before the main investigation. The ground-penetrating radar (Figure 2) and a magnetic prospection device allow the stereoscopic distribution of remains to be determined without excavation. This also allows excavation and preservation of remains to be planned according to the distribution. Explored data is input at site $\mathrm{A}$ and the data is applied to data processing at site $\mathrm{B}$, which supports rapid judgment regarding investigation progress.

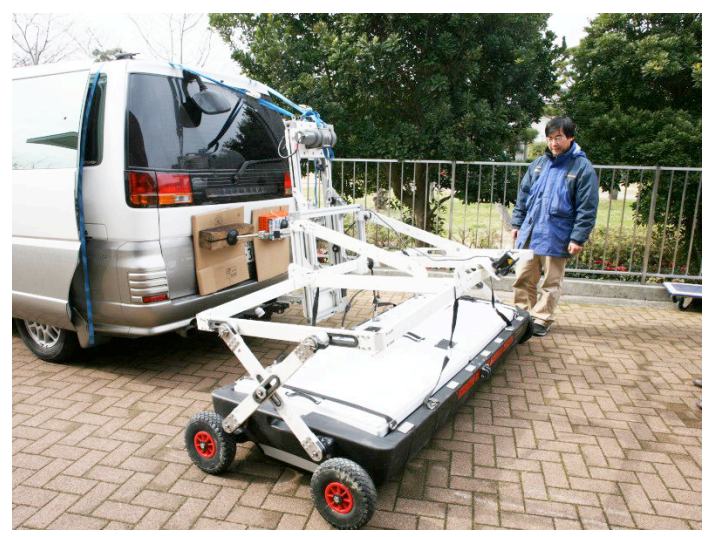

Figure 2. Ground-penetrating radar device

(2) Recording measurement of remains:

A 3-dimensional laser scanner and a digital camera are introduced to measure and record remains. The FARO Focus $3 \mathrm{D}$ is used as the 3-dimensional laser scanner (Figure 3) and the FUJIFILM 3D Measurement System is used as a photogrammetric measurement device (Figure 4). Threedimensional data is input at site A and the data is applied to image processing at site $\mathrm{B}$. The result is shared between both sites. This can eliminate the need to draw remains. Both devices are easy and simple to handle. The devices are attracting attention, although there is room for improvement and operational testing is still needed.

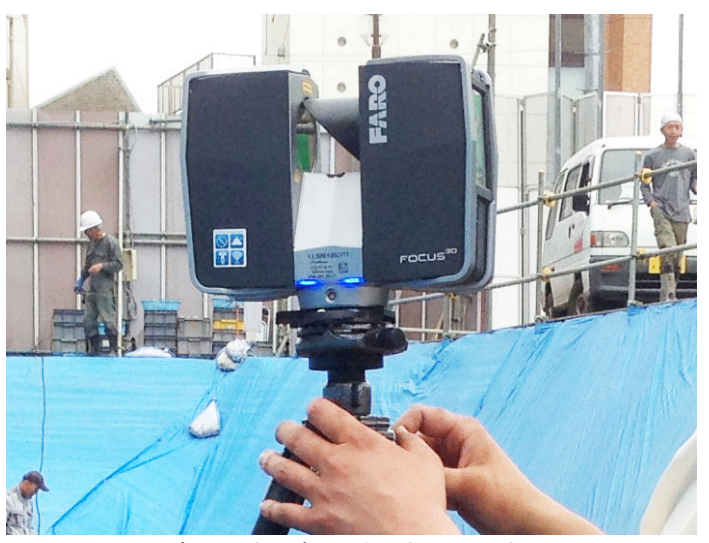

Figure 3. The FARO Focus3D

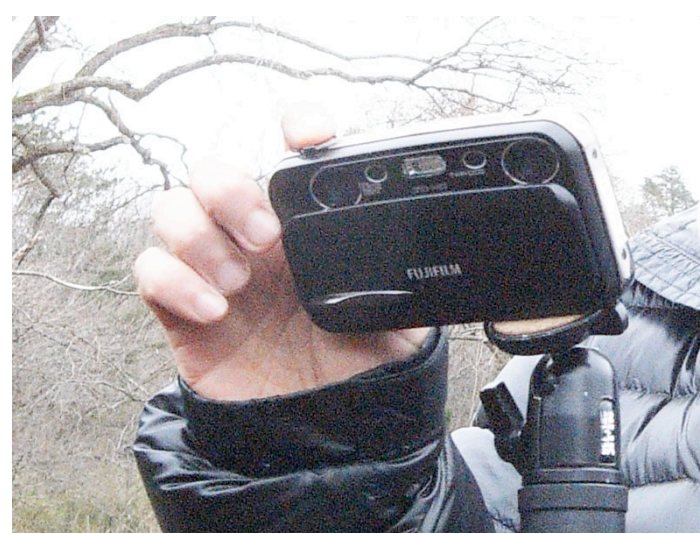

Figure 4. The FUJIFILM 3D camera

(3) Recording measurement of relics:

A 3-dimensional laser scanner is also introduced to measure and record relics. To apply various characteristics of relics, the NextEngine 3D Scanner HD (Kaneda, 2009) and our original devices are used. Three-dimensional data is input at site A and the data is applied to image processing at site B. The result is shared between both sites. Doing so eliminates the need to draw relic shapes.

Underground surveys, 3-dimensional measurements, and image processing are not new technologies in archaeological study, but the authors further improve their performance and implement them in the comprehensive process for excavation and drawing. The authors' goal is the situation where sites A and B are connected to each other with these technologies smoothly implemented as an integrated system.

\section{RESULT AND DISCUSSION}

\subsection{Determining distribution of remains before investigation}

The information obtained by underground surveys varies depending on the types of soil, and the data obtained at each area must be stored to compensate for the variations. In this project, the authors focused mostly on determining characteristics of northeast Japan. We used an array-type ground-penetrating radar and an array-type magnetic prospection device introduced with Grant-in-Aid for Scientific Research for our experiments.

We used the magnetic prospection device in Minami-Soma, Fukushima; the locations of an iron furnace and a charcoal kiln were determined. We were able to determine the distribution of 
remains in broad areas. Figure 5 shows the example of confirming the kiln site after magnetic prospection in Gifu. The data are processed at site $B$.

Ground-penetrating radar has not yet been used at an archaeological site of northeast Japan because of Radio Law restrictions.

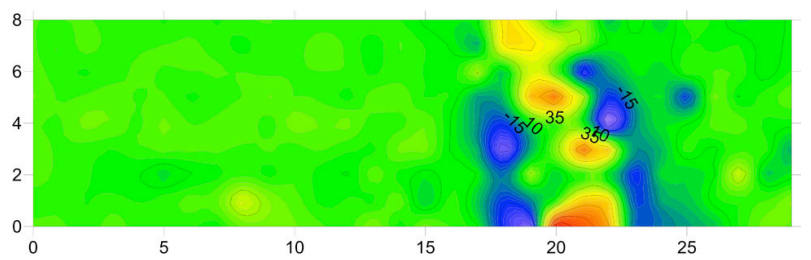

Figure 5. Confirming the kiln site after magnetic prospection

\subsection{Recording measurement of remains}

We had seventeen experimental measurements to record remains (Table 1). Among these sites, the Koshida site in Miyako, Iwate and Moriai's garden are located in the Tsunamiaffected areas. Figure 6 shows how the measurement device is used.

The 3-dimensional data was analyzed using PEAKIT, our original image processing method (Chiba and Yokoyama, 2009). Figure 7(a) shows the PEAKIT image of Moriai's garden.

\begin{tabular}{|l|l|l|}
\hline Site Name & Location & Date \\
\hline $\begin{array}{l}\text { Maruyama B } \\
\text { site }\end{array}$ & Tokyo Pref. & (2013) Jun. 14 \\
\hline Koshida site & Iwate Pref. & (2013) Jul. 9 \\
\hline $\begin{array}{l}\text { Mizugami (2) } \\
\text { site }\end{array}$ & Aomori Pref. & $\begin{array}{l}\text { (2013) Jul. 17, } \\
\text { Aug. 21, 29, Oct. } \\
\text { 3, 14, 25, Nov. 6, } \\
\text { (2014) Jul. 30, } \\
\text { Sep. 23, Oct. 21, } \\
\text { 29 }\end{array}$ \\
\hline Ohinoppara site & Kanagawa pref. & (2013) Aug. 20 \\
\hline Kawaratai site & Aomori pref. & (2013) Aug. 3 \\
\hline $\begin{array}{l}\text { Moriai's } \\
\text { garden }\end{array}$ & Iwate Pref. & May 20 \\
\hline $\begin{array}{l}\text { Nishiura } \\
\text { Ishikiriba site }\end{array}$ & Shizuoka pref. & (2014) Feb. 4 \\
\hline
\end{tabular}

Table 1. Experimental measurements

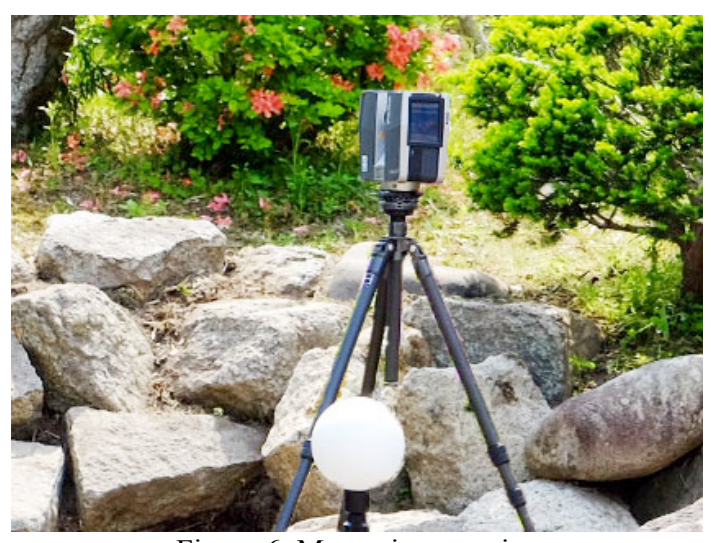

Figure 6. Measuring remains

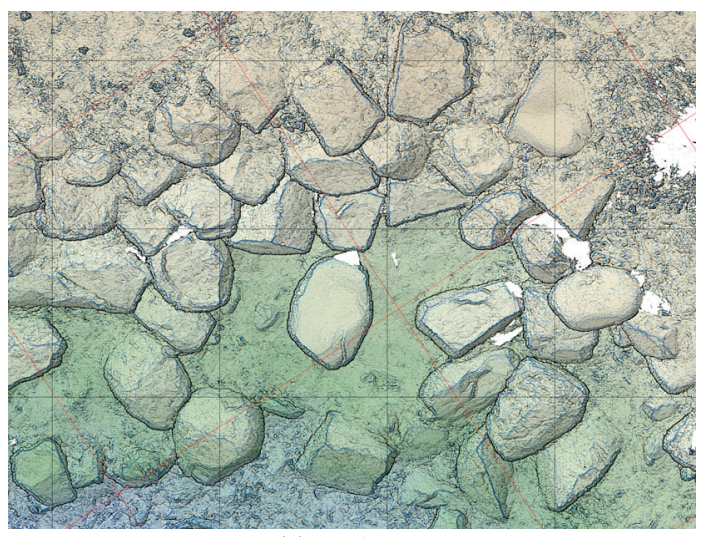

(a) PEAKIT

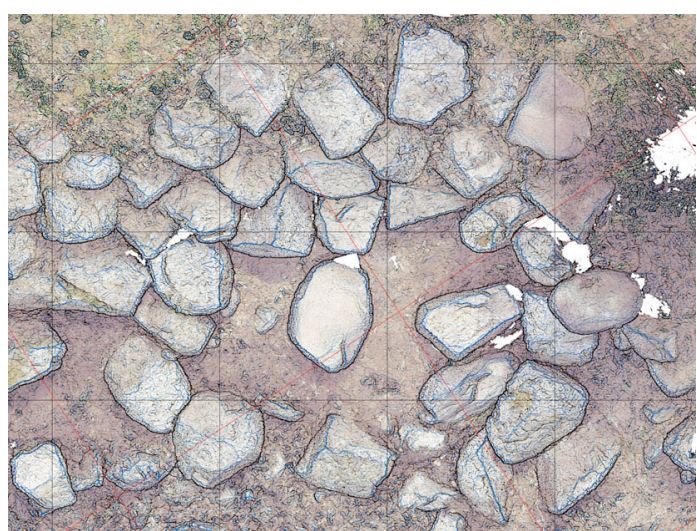

(b) PEAKIT with color information

Figure 7. PEAKIT image of the garden

The FARO Focus3D was introduced to obtain 3-dimensional data of an entire site within approximately hundreds to thousands of square meters. We achieved the following from this device:

(1) We collected know-how in field investigations to acquire appropriate data under various weather conditions such as in rain, wind, or sunsets.

(2) We developed two software applications to process point cloud data obtained from the 3-dimensional laser scanner: one is for interpolating missing data spots and the other interfaces with data processing. Figure 8 shows an example of the result of interpolating software processing.

(3) We developed a method to overlap the color of point cloud obtained by the scanner and the PEAKIT image (Figure 7(b)).

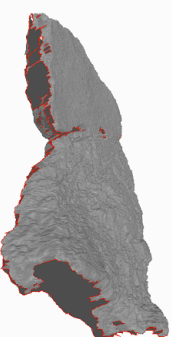

a

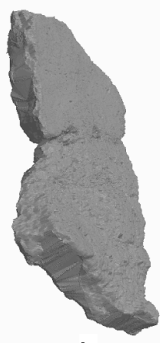

b
Figure 8. Missing data interpolation

The FUJIFILM 3D Measurement System was introduced for cases where specific colors and shape data are required in the range from several tens of centimeters to several meters to record the excavated state of relics or draw soil layer sections. 
This device is used to partially compensate for the data measured by the FARO Focus3D. We achieved the following using the FUJIFILM 3D Measurement System:

(1) We collected know-how to photograph in the environment suitable for constructing $3 \mathrm{D}$ data through repetitive experiments. Fine patterns in the background and physical undulation led to good results.

(2) We developed a software application to construct 3D data from photographs taken using SDK (Figure 9).

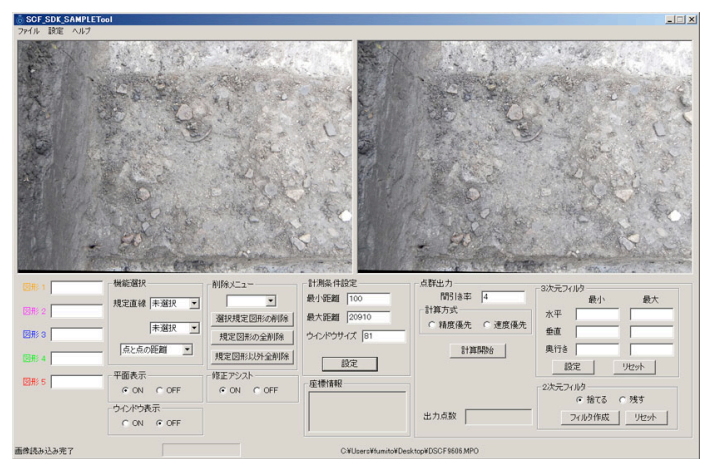

Figure 9. Developed software

(3) We established a method to arrange two or more 3D data pieces and one to project the data to the site coordinate system. The FARO Focus3D data of an entire site (with site coordinate attached) is used as the base and the 3D data of photogrammetric measurement is placed using freeware CloudCompare (Figure 10).

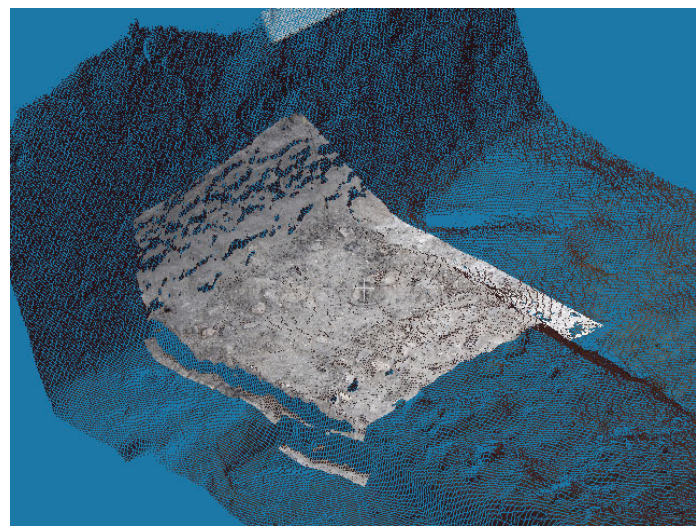

Figure 10. Placing 3D data

(Mitaka City Board of Education, 2015)

\subsection{Recording Measurement of Relics}

We produced two types of 3-dimensional measurement devices: rotational measurement and planar measurement. The suitable device was applied in experiments, depending on relic characteristics. PEAKIT was used to analyze the measured 3dimensional data in the same way as remain analysis.
3.3.1 Rotational 3D Measurement: The NextEngine 3D Scanner HD was introduced for rotational measurement, used for earthenware or other cylindrical relics. We produced a device to enable automatic vertical movement of the NextEngine 3D Scanner HD. Figure 11 (a) shows the device and Figure 11 (b) shows a PEAKIT image of the measurement result of earthenware. To verify rotational measurements, the NextEngine 3D Scanner HD was installed at an in-site excavation office and a wooden product was measured. Figure 12 shows how the measurement was made.

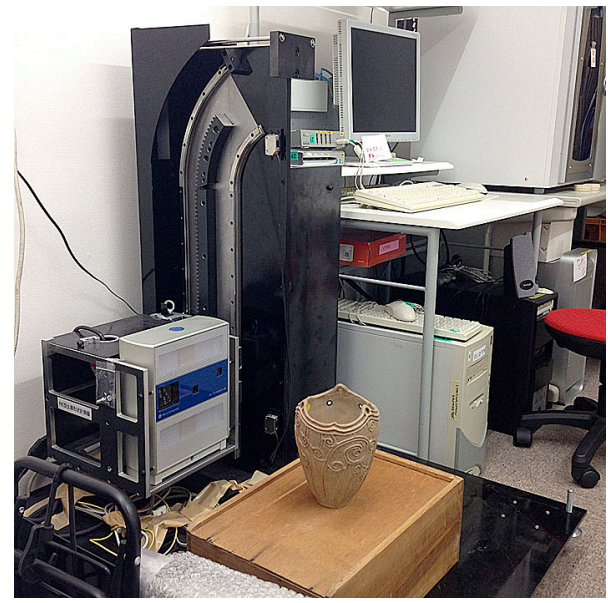

(a) Device

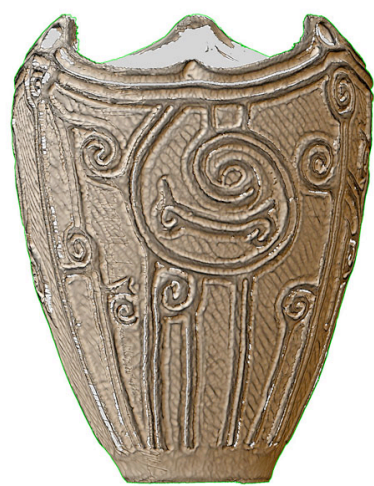

(b) PEAKIT image of the measurement result

Figure 11. Rotational 3D measurement device

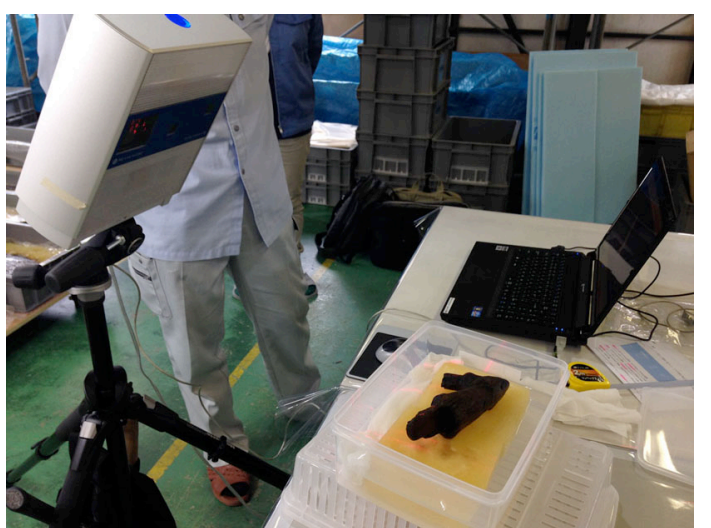

Figure 12. Measurement of a wooden relic by the NextEngine 
3.3.2 Planar-type 3D measurement: The planar type device is used to measure relics that have front and back sides, such as stone tools. Relics are placed on a glass plate and the laser displacement sensor attached to the XY robot measures the relics from the top and bottom of the glass plate. This device follows the mechanism of the stationary device developed by Iwate University and LANG Co., Ltd.; it is downsized to be installed easily at site A (Figure 13). To verify planner measurements, this device was used to measure the stone tools in Mitaka, Tokyo (Figure 14).

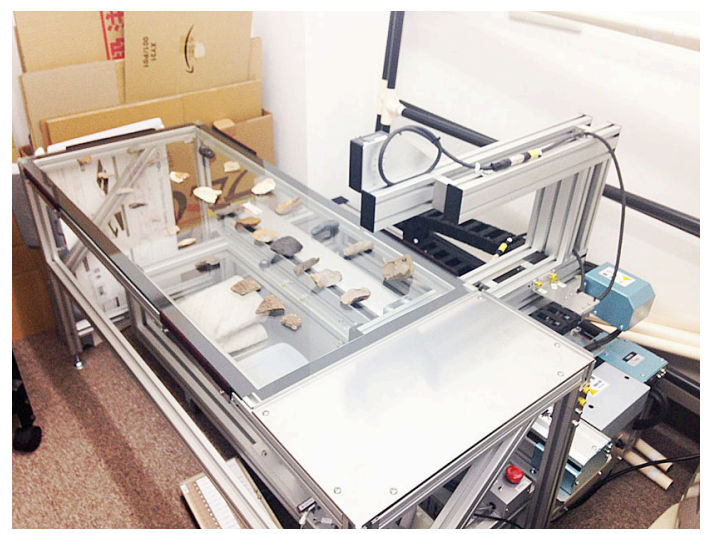

(a) Device

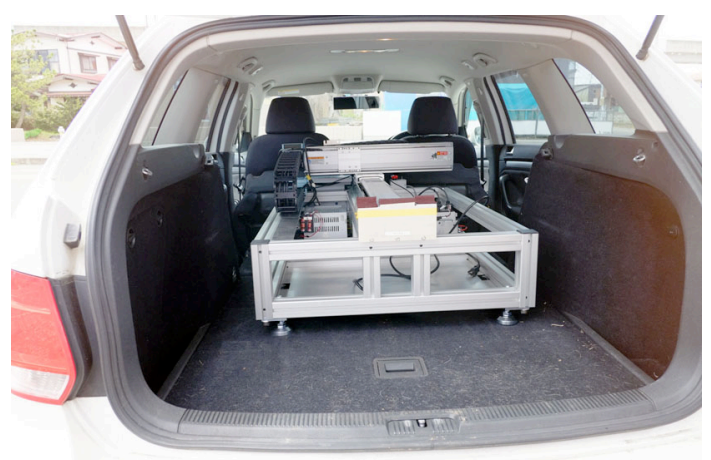

(b) Mounted in a vehicle

Figure 13. Planar-type 3D measurement device

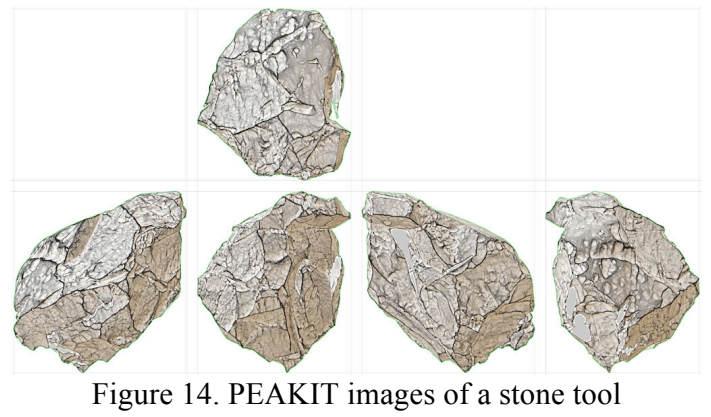

(Mitaka City Board of Education, 2015)

\section{CONCLUSIONS}

As described in this paper, many methods are needed to measure varied archaeological materials effectively while taking into account the characteristics of each object. Many practical experiments revealed that the operation time required at site $\mathrm{A}$ could be significantly shortened. Table 2 compares the traditional and new methods.
We aim to put the "network-type site investigation system" into practical use, with which operations at sites A and B progress simultaneously in parallel. To do so, we will complete the subsystems for each operation and, at the same time, we will work more to share know-how, which includes how to use devices and to transfer and analyze data between the workers at both sites $\mathrm{A}$ and $\mathrm{B}$.

It is obvious that the mechanism proposed in this development helps archaeological investigation and the corresponding report documentation. At the same time, huge numerical information is collected through the investigation process, which is also a significant feature of our project. In the future, we expect this system to be widely used, not only for recovery from disasters, but to produce new social values in digital archives of academic information and educational promotion projects.

\begin{tabular}{|c|c|c|}
\hline $\begin{array}{l}\text { Work } \\
\text { descriptions }\end{array}$ & $\begin{array}{l}\text { Traditional } \\
\text { methods }\end{array}$ & New methods \\
\hline $\begin{array}{lr}\text { Drawing } & \text { of } \\
\text { excavated } & \text { state } \\
\text { of relics } & \end{array}$ & 9.5 hours & $\begin{array}{l}10 \text { minutes } \\
\text { (FUJIFILM 3D) }\end{array}$ \\
\hline $\begin{array}{l}\text { Drawing of } \\
\text { remains }\end{array}$ & 44 hours & $\begin{array}{l}7 \text { hours } \\
\text { (Focus3D) }\end{array}$ \\
\hline $\begin{array}{l}\text { Drawing of } \\
\text { wooden relics }\end{array}$ & 19.5 hours & $\begin{array}{l}6 \text { hours } \\
\text { (NextEngine) }\end{array}$ \\
\hline $\begin{array}{ll}\text { Drawing } \\
\text { stone tools }\end{array}$ & 20 hours & $\begin{array}{l}4.17 \text { hours } \\
\text { (Planner-type) }\end{array}$ \\
\hline
\end{tabular}

Table 2. Working Time at Side A

\section{ACKNOWLEDGEMENTS}

This research is made possible by the program to promote postearthquake revitalization of Japan Science and Technology Agency.

\section{REFERENCES}

Chiba, F., and Yokoyama, S., 2009. New Method to Generate Excavation Charts by Openness Operators. 22nd International CIPA Symposium, Kyoto, Japan.

Kaneda, A., 2009. Application of A Low Cost Laser Scanner For Archaeology In Japan. 22nd International CIPA Symposium, Kyoto, Japan.

Mitaka City Board of Education, 2014. Hanezawadai Site, Hanezawadai Tunnel Tombs Group 3 Site 2. Mitaka, Japan (in Japanese).

Mitaka City Board of Education, 2015. Maruyama B Site 2. Mitaka, Japan (in Japanese). 